0 presente trabalho tem como objetivo discutir quais processos psíquicos estão envolvidos a fim de que 0 acesso à língua de sinais e à escrita alfabética para o surdo ocorra, a partir de um caso clínico. Ao problematizar-se esta questão, vêm a tona discussões específicas sobre a língua de sinais e sobre as possíveis dificuldades de apropriação da escrita para o surdo. Pudemos verificar como a apropriação desses recursos, contrapondo-se a essas adversidades, pode trazer ganhos psíquicos, culturais e sociais para o surdo.

Surdez; língua escrita; língua de sinais; constituição subjetiva

SIGN LANGUAGE AND WRITING - POSSIBILITIES OF SAYING ABOUT THEMSELVES FOR DEAF PEOPLE

The goal of this article is to discuss which psychic processes are involved in order to promote sign Language and alphabetical writing acquisition (or access) based on a clinical experience. When these questions are raised, it comes out the specific matters about Sign Language and the possible difficulties on writing appropriation by a deaf person. 0 pposite to these adversities, we had noticed that these re sources appopriation could lend to psychic, cultural and social profits for the deaf person.

D eaf; writing; Sign Language; subjective construction

\section{A LÍNGUA DE \\ SINAIS E A ESCRITA \\ - POSSIBILIDADES \\ DE SE DIZER, \\ PARA O SURDO}

\author{
Clarissa D egrazia $C$ arvalho \\ Yone $M$ aria Rafaeli
}

$1 Y$

este artigo pretendemos desenvolver considerações sobre a constituição e 0 aprendizado da língua, da leitura e da escrita para 0 surdo, a partir de um caso clínico. Trataremos da língua de sinais, que no caso dos surdos seria sua língua social, que 0 ajudará a organizar seu psiquismo e seu contato com a cultura e o desenvolvimento do conhecimento, tornando-se para eles, nas palavras de Rassial (2002), "a língua como organizadora do inconsciente" (p. 9).

Psicóloga e aprimoranda do Serviço de Psicologia da Divisão de Ensino e Reabilitação dos Distúrbios da Comunicação (Derdic), da PUC-SP.

- - Psicóloga, psicanalista, membro da equipe do Serviço de Psicologia da Derdic, membro do Departamento de Psicanálise do Instituto Sedes Sapientiae e membro da Associação Paulista de Estudos Psicanalíticos (Apep). 
Em relação à língua, à leitura e à escrita, vamos pensá-las não como algo separado do indivíduo, exterior a ele, que precisaria apenas ser aprendido, mas a escrita e a leitura sofrendo processos similares à aquisição da língua e também fazendo parte das condições para a estruturação subjetiva.

Em uma referência feita por Pommier (1993), encontramos que "a língua 'não se aprende' no sentido usual do termo, porque é a linguagem que constitui 0 objeto desta iniciação e que o sujeito mesmo faz parte deste objeto. A poderar-se da língua é um feito cultural, ainda que, por outro lado, cada criança se introduza na palavra de acordo com seu ato de apreensão próprio" (p. 9)1․ Isto é, não vamos tomar o sujeito como passivo nesse ato, mas sim ressaltar os efeitos que a apropriação da língua e da escrita tem sobre a subjetivação e, nesse caso, quais processos psíquicos se fizeram necessários para que a língua e a escrita pudessem advir.

$\mathrm{N}$ ão vamos considerar a escrita apenas como um código de representação da fala, até porque sabemos que em qualquer língua sempre existe uma distância entre a língua falada e a escrita, e no caso da língua de sinais isto vai um pouco além, pois a Língua Brasileira de Sinais (Libras) não é o português sinalizado, mas sim uma língua que tem uma gramática e estrutura própria.

A língua de sinais seria, segundo Viader, Pertusa e Vinardell (1999), a "língua própria das pessoas surdas, usando sua estrutura, sintaxes e gramáticas próprias, sem o uso simultâneo e alternativo da língua falada. Respeita-se seu status lingüístico como língua. Se expressa com elementos prosódicos e reflexões próprias" (p. 54).

Além disso, é importante ressaltar ser a língua de sinais essencialmente visual, motora e espacial. E ainda temos de considerar que muitos surdos não têm acesso à Libras, desenvolvendo somente uma comunicação mímica ou gestual. E que é extremamente comum 0 acesso tardio e a demora da aceitação da Libras, já que muitas vezes as famílias não buscam este recurso e não se comunicam com a criança dessa forma.

Então, se pensássemos a escrita como código representante da fala, não seria possível para o surdo escrever dentro das regras gramaticais do português, e sim apenas transcrevendo a gramática da língua de sinais, o que não seria nem um pouco útil, pensando na questão da possibilidade de que seu texto pudesse ser compreendido e incluir-se no meio social composto pelos leitores ouvintes.

Pommier (1993), ainda em relação à língua escrita, entenderá esta como mais uma formação do inconsciente. D a mesma 
forma que os sonhos e os desenhos, seriam as letras alfabéticas. Afirma que "quando realiza um traçado, a criança se representa e apresenta em primeiro plano seus sonhos; seus desenhos delineiam-se segundo as dimensões oníricas que ela projeta: a evolução de suas representações segue então o mesmo trajeto que seus sonhos cujas lembranças sucumbem sempre mais ou menos ao recalque. Sabemos o que acontece com nossos sonhos: nós os esquecemos a quase todos, porque põem em cena um gozo que ocultamos. D a mesma maneira se os primeiros desenhos têm um valor idêntico ao dos sonhos, eles também não serão produto do recalque cujo resto será a escrita?" (p. 10).

A partir dessa afirmação, vemos que seria necessária a incidência do recalque para que a escrita pudesse comparecer. 0 desenho da letra precisaria ser recalcado para que este assumisse 0 valor de letra alfabética, como uma letra representante de algo em um sistema socialmente compreendido, e não funcionasse apenas como um desenho.

Para Pommier, "em geral se coincide a respeito de definir a letra com o que se vê e depois com o que se ouve graças à leitura, mas essa qualidade auditiva não especifica ainda que a pronúncia seja seu produto final, tecnicamente utilizável. M ostrar-seá que a característica da letra não é nem visual nem auditiva, que ela depende de seu lugar de origem, do recalque, de sua forma, quer dizer, do retorno do que foi recalcado do gozo do corpo. As qualidades auditivas ou visuais da letra são somente conseqüências desta característica" (p. 105).

Seguindo esse pensamento, teríamos que nos perguntar: qual seria o estatuto da palavra ouvida, enquanto imagem acústica, na produção da escrita? Teríamos uma estrutura independente da palavra sonora, ou se trataria sim, como afirmou Pommier, do efeito do recalque? Em contraposição, como afirma Goldgrub (2001), "o caráter secundário da escrita em relação à fala, em termos tanto filogenéticos como ontogenéticos, torna mais do que plausível a hipótese da precedência da oralidade. É lícito, portanto, postular que a oralidade constitui a condição de emergência do nível significante" (p. 216).

$\mathrm{N}$ a representação da língua oral e da língua escrita, podemos pensar que na construção da vida psíquica e no acesso à língua escrita, para fazer os primeiros traços de desenho, é necessário que o sujeito tenha sido objeto da língua de um outro, e tenha construído uma primeira imagem corporal, que foi falada e desejada por $\mathrm{O}$ utro. A representação do corpo tem que ter atravessado o espaço do recalque para ressurgir em forma de letras. Pôr algo em imagem é despir-se, deixar cair o corpo. 
N ossa hipótese de trabalho na condução desse caso é que para o surdo seja necessário recalcar a imagem pictográfica representada na língua de sinais, a fim de que a palavra gestualizada possa assumir um outro valor, no caso, o de letra alfabética.

Joana tem 11 anos e chegou à D ivisão de Ensino e Reabilitação dos $D$ istúrbios da Comunicação (D erdic), aos 9 anos, com sérias dificuldades de comunicação, por não ter o domínio nem da língua de sinais, nem da escrita.

$\mathrm{N}$ os primeiros atendimentos era surpreendente sua esperteza, vivacidade corporal e mímica, mas que, ao mesmo tempo, se perdiam pela dificuldade de ela ser compreendida. Sempre demonstrou um extremo interesse pelas letras, porém, apenas copiava o que encontrava escrito pela sala e escrevia muitas vezes seu nome e 0 de seus pais. Com o tempo, notou-se que Joana apenas havia memorizado as formas das letras, mas não as conseguia ler, e tampouco as conhecia na língua de sinais.

D urante o processo terapêutico e 0 atendimento fonoaudiológico, Joana aprendeu a escrever a língua portuguesa e a utilizar a língua de sinais.

Esse processo levou-nos a formular algumas perguntas: que efeito teve a apropriação da escrita e da língua de sinais em sua posição subjetiva? quais foram os processos que facilitaram o acesso à língua de sinais e à escrita alfabética?

$Q$ uanto à escrita alfabética, percebemos que ela pôde aparecer de- vido às condições anteriormente mencionadas, do efeito do recalque, já que sem ele o sujeito que vê os signos literais ficaria preso à sua forma e conseqüentemente não chegaria a retirar seu valor pictográfico para dar lugar a uma possibilidade de significar.

0 efeito do recalque sobre ela fez cair a forma da letra para que esta pudesse assumir um valor significante e ganhasse a possibilidade de significar "um" em relação aos outros elementos (letras) do sistema alfabético.

Bergès e Balbo (1996), no texto "D o corpo à letra", acrescentam que a letra será, ela também, uma portadora da lei, porque se encontra em um sistema compartilhado culturalmente. Para tal, é necessário que a criança deixe-se capturar, entre neste sistema, renda-se à castração, para poder escrever.

É interessante pensar que a questão das leis e regras era uma das maiores dificuldades de Joana. Seus pais, justificando suas atitudes a partir da surdez, muitas vezes não conseguiam interditá-la. Por exemplo, no dia de seu 10 aniversário, seus pais, não estando em condições de lhe fazer uma festa, optaram por não Ihe contar que era o dia de seu aniversário, para que não sofressem ao ver que deixariam sua filha em falta. $E$ assim muitos outros exemplos aconteceram, mas o que importa é que J oana possuía um lugar específico em sua casa pelo fato de ser surda: ela tinha tudo o que seus irmãos não tinham, e ficava muito nítida a dificuldade dos pais em frustrá-la. 
É possível que essa dificuldade decorra do fato de a surdez ser tomada por eles como uma falta já evidente, no plano real, e então a realização de todos os seus desejos teria o lugar de preencher essa falta.

D urante as sessões, J oana sempre queria mexer nas caixas das outras crianças, e, diante do impedimento, ela dava uma voltinha e acabava olhando o que os outros tinham em suas caixas. Da mesma forma, no final das sessões em que ela decidia que queria brincar de tudo e, quando acabava o tempo e teria de ir embora, isto é, ela não poderia brincar com tudo, ela não agüentava, ficava implorando por mais tempo e muitas vezes saía da sala ainda desenhando na mão aquilo que não havia dado tempo de desenhar. Ela não suportava a frustração, a entrada de uma ordenação, como a do tempo cronológico, e reagia, sempre dando um jeitinho, supondo que seria possível conquistar aquilo cujo acesso the estava sendo limitado.

O utra postura de Joana que deixa muito clara essa posição de não suportar a frustração é mostrada pelo fato de ela sempre saber de tudo, de não haver nada que ela não soubesse ou tivesse esquecido. Suas respostas eram sempre muito diretas, rígidas e fixas, como se, para cada pergunta, houvesse uma única resposta, e a sua era sempre a correta. M esmo que não tivesse entendido 0 que lhe fora dito ou quando era posta em dúvida, ela não respondia e se desviava indo fazer outras coisas.

Tomando esses conteúdos, vemos como Joana não podia perder, prescindir de nada, abandonar sua posição diante da castração.

Sua posição quanto à escrita também vem exemplificar isso. Muitas vezes sua escrita parecia um desenho, em que ela ia copiando as letras, na maior perfeição, sem deixar existir qualquer diferença entre 0 que ela havia escrito e o papel onde copiava. Tinha de ficar tudo perfeito, preenchido. Parecia presa, cristalizada apenas no visual, o que é mais imediato, não permitindo muito espaço, nem equívoco, nem outros desdobramentos da linguagem, em que a castração pudesse incidir, e 0 sujeito pudesse aparecer.

J oana estava presa no imediatismo desse saber, do saber visual que Ihe dava um sentido fixo. Suspender este imediatismo, para que a falta e a dúvida pudessem aparecer, era a condição para dar lugar à aprendizagem, e, com esta, veicular novos sentidos.

Com a entrada da língua de sinais em seu repertório, o aprendizado da escrita foi podendo acontecer, isto porque a entrada dessa língua trouxe a Joana a possibilidade dessa suspensão, e o movimento da língua foi-Ihe impondo os espaços e intervalos próprios de seu funcionamento.

A entrada de uma língua que tem uma lei, um sistema, retira Joana do imediatismo. 0 que era apenas uma comunicação (em que as coisas só tinham um sentido fixo) foi se tornando linguagem, um signo passou a ter vários significados, as diferenças passaram a ter existência, e o simbólico pôde se instalar.

$M$ as foi principalmente com a aprendizagem da escrita que a mu- 
dança aconteceu. Ainda na língua de sinais, Joana se mantinha na posição da "sabida"; quando Ihe era perguntado sobre algum sinal que ela não conhecia, ela inventava, antecipando-se num domínio da língua. A dúvida ainda não existia, tornando muito difícil a aprendizagem da língua de sinais, pois ela mantinha-se na posição de que já sabia tudo, sustentando-se ilusoriamente na comunicação, marcando que a diferença só existia porque a terapeuta é que não tinha entendido, atribuindo o equívoco ao outro.

Só que na apreensão da escrita isso não aconteceu. Joana passou a entrar em dúvida, a querer que as coisas escritas por ela fossem lidas, para ver se estavam corretas; permitia que fosse corrigida e passou a dizer muitas vezes que não sabia, mas se mostrava muito interessada em querer saber.

D iante dessa questão da diferença de sua posição na escrita e na língua de sinais, levantamos a hipótese de que tenha algo do desejo dos pais, já que seus pais só sustentaram 0 atendimento para que $J$ oana aprendesse a ler e escrever, e, como eles não sabem a língua de sinais, a mãe sempre dizia o quanto Ihes facilitaria a comunicação se J oana soubesse ler e escrever. Um outro ponto importante a ser ressaltado sobre essa questão é que todas as mulheres de sua família sabem ler e os homens não, e que o pai de J oana nunca podia trazêla aos atendimentos, porque não saberia ler o nome do ônibus, e a mãe sempre acrescentava: "Se ela já soubesse ler, tudo seria diferente". O u seja, é aí, numa an- 
tecipação imaginária, no lugar de quem tem de aprender a ler, em que estão o desejo e o olhar de sua mãe para Ihe conferir uma condição de identificação feminina, que Joana vai então tentando corresponder. É aí que pode suportar perder, para aparecer em outro lugar. Lugar em que foi investida e objeto de desejo. Lugar em que o desejo foi ordenado. Ela pôde perder-se em um lugar, para se deixar surgir lá onde o desejo suporta a falta. 0 que é muito interessante nesse aprendizado é perceber que a escrita pôde funcionar como alternativa possível para Joana retomar, ou talvez completar, sua constituição. Já que o trabalho da escrita, ao seguir o rumo do alfabetismo, pôde incluí-la no sistema simbólico, por meio da ampliação de sua possibilidade significante.

A língua de sinais e a escrita, em última instância, possibilitaram a Joana uma efetivação do recalque, e garantiram um modo de se posicionar em relação ao discurso social e cultural. A estruturação subjetiva pôde se modificar por meio da língua de sinais e da escrita, ampliando suas cadeias significantes, retirando-a de um movimento de causa e conseqüência, em que as respostas ficavam fixas, em que não havia flexibilidade; e isso impedia sua circulação pela linguagem.

U m exemplo dessa mudança de Joana fica claro em uma das sessões em que ela, por meio de uma criação chistosa na língua de sinais, provoca, com uma "carinha" irônica, perguntando que sinal estava fazendo. Diante da resposta de que era uma tartaruga, ela dá muita risada e diz que enganou a terapeuta, e que na verdade aquilo é um tatu, porque tem o rabinho. $\mathrm{N}$ a realidade, 0 que Joana faz agora é brincar com a língua de sinais, podendo enganar o outro, trazendo um outro sentido, em que ela acha graça no engano, porque os sinais de tartaruga e tatu são exatamente iguais, só mudam a parte de trás em que tatu tem um rabinho que ela escondeu, mostrando apenas a parte da frente. Com o riso e o engano do outro, ela encontra prazeres que se obtêm e se abrem quando se participa da língua, podendo produzir, com ela, jogos que as palavras-gestos-sinais partilhados podem expressar. 0 fato de ter enganado um outro restaura-lhe e confirma-lhe seu trânsito por uma língua que pode ser transgredida, já que as palavras portam muitos sentidos. Esta sim é a transgressão possível e que garante o prazer do desejo infantil.

E interessante ver como a língua de sinais e a escrita possibilitaram-Ihe um maior distanciamento de suas inscrições antes tão fixas, a ponto de poder brincar com elas, o que lhe traz um outro modo de produção em sua cadeia significante, havendo a possibilidade de ser reconhecida no discurso social, de se dizer e, assim, se é possível falar desta forma, de ficar mais livre e feliz. 
Bergès, J. \& Balbo, G . (1996). D u corps à la lettre. Revuedel'Association F reudienne: $L a$ Psychanalyse de l'Enfant. La question du père, aujourd'hui, no 20, pp. 181-208.

Goldgrub, F. W. (2001). A máquina do Fantasma (aquisição de linguagem e constituição do sujeito), língua de sinaise aquisição de linguagem. Piracicaba, SP: Editora U nimep, pp. 203-31.

Pommier, G . (1993). N acimiento y renacimiento de la escritura. Buenos Aires: N ueva Visión, pp. 7-15.

Rassial, J.J. (2002). 0 que osadolescentes ensinam aos analistas. Ciclo de D ebates. São Paulo, SP: Lugar de Vida, Instituto de Psicologia-USP, pp. 59-76.

Viader, M . P. F.; Pertusa, E. \& Vinardell, M . (1999). In Skliar, C. (org.). Atualidade da educação bilíngüe para surdos. Porto Alegre, RS: M ediação, pp. 47-57.

NOTAS

1 Tradução livre feita pelas autoras.

Recebido em maio/2003. A ceito em julho/2003. 